Special Issue of the 6th International Congress \& Exhibition (APMAS2016), Maslak, Istanbul, Turkey, June 1-3, 2016

\title{
Mathematical Modeling of Heat Effect on Cable Insulation
}

\author{
E. EROGLU ${ }^{a} *$, I. GuneY ${ }^{b}$, I. Gunes ${ }^{c}$ And E. Sener ${ }^{a}$ \\ ${ }^{a}$ Kirklareli University, Faculty of Arts and Science, Department of Mathematics, Kirklareli, 39000 Kirklareli, Turkey \\ ${ }^{b}$ İstanbul Sabahattin Zaim University, Faculty of Business and Management Sciences, \\ Department of Management, İstanbul, Turkey \\ ${ }^{c}$ İstanbul University, Faculty of Engineering, Department of Electrical and Electronics, İstanbul, Turkey
}

\begin{abstract}
In the electric power industry, the cost of energy, its longevity and safety of transferring are important problems. Security problems, environmental effects, discharging occurrences and the endurance of the transporters are the problems that exist as a consequence of the high voltage necessity for the transmission of big amounts of energy and which need to be solved. ADSS (all dielectric self-supporting) cables are generally installed on high voltage transmission lines. They are mostly used in such situations, as high temperature, strong winds and direct sunshine and, as the effect, the UV radiation, etc. The solid materials are in use more frequently than gas or liquid ones. Decent dielectric materials need to be sturdy to puncturing and highly invulnerable for mechanical issues. Moreover, they have to perform and resist well the chemical reactions and high temperature, so that they would not be easily effected by the environmental factors. In this study, the mathematical modeling of heat effects on ADSS cables is investigated by using dry band arcing (IEEE 1222 Electrical surface degradation) test method. A heat source is introduced into the test setup, to evaluate the performance of poly-ethylene cable jackets on ADSS cables at different temperatures. Test results indicate that the endurance of the ADSS cables decreases with the increasing temperature.
\end{abstract}

DOI: 10.12693/APhysPolA.131.539

PACS/topics: 02.90.+p, 88.20.td

\section{Introduction}

The purpose of this study is to discus the mathematical model, related to the ageing duration of the ADSS cables, used for energy transmission in the industry, under the effect of increased temperature in a laboratory setup. Models of mathematical experimental design-related engineering are described in $[1,2]$. These are basic models and remarkable guides to perform the appropriate mathematical design of experiments. Designed experiment provides scientific results faster than the other experiments, because mathematical modeling enables researchers to gather the same results as in real experiments and to save time and money. Electrical energy transmission $[3,4]$ and fatigue [5] are rigorously studied. This study is focused on the heat effect only.

Cables are classified as low, medium, high and extra high voltage power cables [6]. All types of power cables are subjected to electrical, thermal, mechanical and environmental stresses, due to conditions of the cable guiding system, external environmental conditions, high currents and voltages. Ageing of the cable insulation, under above mentioned stresses, limits their lifetime. The installation and manufacturing costs of such cables are very high compared to aerial cables. Therefore one expects to have longer lifetimes under high currents [7] in such cables. The cable insulation usually consists of impregnated paper, synthetic polymers (polyethylene (PE), cross

*corresponding author; e-mail: emreeroglu@klu.edu.tr linked polyethylene (XLPE), ethy-lene propylene rubber $(\mathrm{EPR}))$ and compressed gases $\left(\mathrm{SF}_{6}\right.$, Freon, $\left.\mathrm{N}_{2}\right)$ [8].

In a power cable there are two heat sources which degrade the cable insulation [9]. These are the heat generated in the conductor due to resistive losses, caused by the load current, and heat generated in the insulation due to dielectric losses [10]. The cable will absorb a part of the total heat generated and the rest will be dissipated to the surrounding medium. The insulation might be heated to such a high temperature that it changes physically [11].

The insulation community has a great interest in predicting the life of insulation at normal operating stresses, from relatively rapid tests performed at higher than normal operating stresses. Life prediction at normal stresses requires a mathematical model to extrapolate the accelerated ageing life to lower stresses. Unfortunately, since the lifetimes of the apparently identical cable specimens, tested under the same conditions, can vary by over an order of magnitude from specimens to specimens, there is a considerable difficulty to select the best model and to objectively calculate the ageing model parameters $[12,13]$. In this study, a review of ageing phenomena in electrical insulation systems and models used in lifetime studies of solid insulators under single and multiple stress conditions are presented. The statistical methods used with this type of data are briefly described.

Cables are mostly used under different environmental effects, such as temperature, wind, vibration, etc. In this study, effect of different levels of heat on cables was investigated by using dry band arcing (IEEE 1222 Electrical surface degradation) test method and the obtained data was mathematically modeled. The performance of cable jacket is tested under different heat conditions [14]. 
Utilities frequently introduce links on high voltage transmission lines. The links are generally introduced 10-20 feet underneath the high voltage conductors. A grounded protection pole is backing the link at every tower. A corona curl is utilized to stifle the corona discharge at the ends of the protective bars. At the point where the link gets dirtied and wet, there exists a capacitive coupling between the transmission line and the link and between the link surface and the ground. High voltage is induced on the surface of the link [15]. The voltage difference between the grounded protection pole and the affected voltage on the link drives a current along the surface of the link.

In the drying link appear little dry-regions, which stand in the path of current. In case when the voltage, across the dry-band, is large enough, an arc is created over the dry band. The heat created by the dry-band arcing destroys the link coat after some time. Studies have demonstrated that dry band arcing happens when the link is wet and dirtied. The current before dry-band arcing is around $1 \mathrm{~mA}$ and is considerably higher when the longitudinal electric field is large enough to arch over the dry band.

Computer models have been produced to ascertain the voltage and current dissipation of the framework. These models permit expectation of dry-band arcing on links. Inputs to this model incorporate the physical course of action of the link on the high voltage lines. The affected streams and voltages rely upon temperature level [16].

\section{Method, materials and modeling}

The first considered data set is for the two hours from the start of UV exposure, which contains measurements made with an interval of 10 minutes. Second data set consists of the effect of aging duration of a cable, exposed to heating and cooling cycles. Temperature values are given in ${ }^{\circ} \mathrm{C}$.

TABLE I

Anova (analysis of variance).

\begin{tabular}{c|c|c|c|c|c}
\hline \hline Model & $\begin{array}{c}\text { Sum of } \\
\text { squares }\end{array}$ & df & $\begin{array}{c}\text { Mean } \\
\text { squares }\end{array}$ & F & Significant \\
\hline Regression & 198450.000 & 1 & 198450.000 & 106.550 & 0.000 \\
Residual & 29800.000 & 16 & 1862.500 & & \\
Total & 228250.000 & 17 & & &
\end{tabular}

The analysis of variance values of temperature are shown in Table I. One can see from the Table I that regression coefficients are significant. Table I demonstrates that both models fit and how much of the residuals are explained by the variables in the nonlinear regression model. It can be also observed from Table I that nonlinear regression model is significant. Thus, there is no reason to reject the model.

There are no such effects selected in aging but effect of heat is significant in Table II.
TABLE II

Regression coefficients.

\begin{tabular}{|c|c|c|c|c|c|}
\hline & \multicolumn{2}{|c|}{$\begin{array}{c}\text { Coefficients } \\
\text { (unstandardized) }\end{array}$} & \multirow{2}{*}{$\begin{array}{c}\text { Coefficients } \\
\text { (standardiz.) } \\
\text { Beta }\end{array}$} & \multirow[t]{2}{*}{$\mathrm{T}$} & \multirow[t]{2}{*}{ Signif } \\
\hline & $\mathrm{B}$ & Std. error & & & \\
\hline (Const.) & 983.333 & 32.167 & & 30.570 & .000 \\
\hline TIME & -210.00 & 20.344 & -0.932 & -10.322 & 0.000 \\
\hline
\end{tabular}

The model of aging effect is: Aging Effect $=983.333-$ $210 \times$ TIME. Multiple determination coefficient $R$ is 0.966 .

The independent variable is TIME. According to Table III, one reject $H_{0}$ : all coefficients are not significant, thus coefficients is significant.

TABLE III

Anova (analysis of variance).

\begin{tabular}{c|c|c|c|c|c}
\hline \hline Model & $\begin{array}{c}\text { Sum of } \\
\text { squares }\end{array}$ & df & $\begin{array}{c}\text { Mean } \\
\text { squares }\end{array}$ & $\mathrm{F}$ & Significant \\
\hline Regression & 5.163 & 1 & 5.163 & 1504.550 & 0.000 \\
Residual & 0.038 & 11 & 0.003 & & \\
Total & 5.201 & 12 & & &
\end{tabular}

The dependent variable is $\ln \left(\frac{1}{\text { TEMP }}\right)$. TEMP is temperature $\left({ }^{\circ} \mathrm{C}\right)$.

TABLE IV

Regression coefficient.

\begin{tabular}{c|c|c|c|c|c}
\hline \hline & \multicolumn{2}{|c|}{$\begin{array}{c}\text { Coefficients } \\
\text { (unstandardized) }\end{array}$} & $\begin{array}{c}\text { Coefficients } \\
\text { (standardiz.) }\end{array}$ & $\mathrm{T}$ & Significant \\
\cline { 2 - 3 } & $\mathrm{B}$ & Std. error & Beta & & \\
\hline (Const.) & 0.050 & 0.002 & 0.369 & 32.565 & 0.000 \\
TIME & 0.983 & 0.000 & & 2302.682 & 0.000
\end{tabular}

TABLE V

Comparison table of lifetimes.

\begin{tabular}{c|c|c}
\hline \hline \multirow{2}{*}{$\begin{array}{c}\text { Test } \\
\text { sample }\end{array}$} & \multicolumn{2}{|c}{ Lifetime of test sample } \\
\cline { 2 - 3 } & under normal condition & under heat effect \\
\hline A & $24 \times 30=720$ minutes & $19 \times 30=570$ minutes \\
B & $27 \times 30=810$ minutes & $21 \times 30=630$ minutes \\
C & $27 \times 30=810$ minutes & $19 \times 30=570$ minutes \\
D & $25 \times 30=750$ minutes & $20 \times 30=600$ minutes \\
E & $24 \times 30=720$ minutes & $20 \times 30=600$ minutes \\
F & $26 \times 30=780$ minutes & $19 \times 30=570$ minutes \\
G & $27 \times 30=810$ minutes & $17 \times 30=510$ minutes \\
H & $27 \times 30=810$ minutes & $18 \times 30=540$ minutes \\
I & $25 \times 30=750$ minutes & $16 \times 30=480$ minutes \\
Average & 773.33 minutes & 563.33 minutes
\end{tabular}

Temperature dependent test results, under normal conditions, are shown in Table $\mathrm{V}$. The average lifetime of the cables is normally 773 minutes, while after the heat effect it drops to 563 minutes. Therefore, the insulation lifetime of the cables is reduces by $27 \%$ when they get tired by the heat effect. 
In a nonlinear regression model, the magnitudes of coefficients are $a$ (const) $=0.50$ and $b$ (TIME) $=0.983$. Table IV shows that both parameter estimates are significant. Model is $\ln \left(\frac{1}{\text { TEMP }}\right)=0.05+0.983 \times$ TIME. Figure 1 presented below is a curve shown as a model logistic.

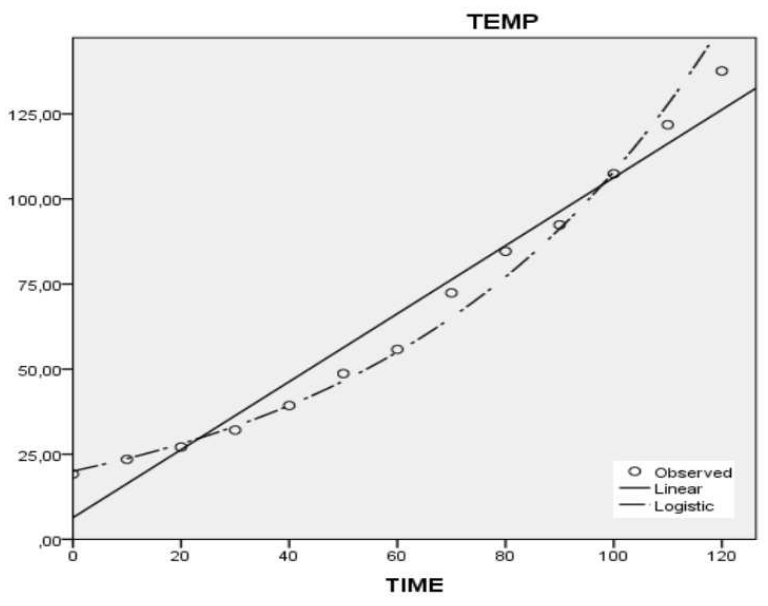

Fig. 1. Graph of model for data.

\section{Conclusions}

This study is focused on the change of ageing duration of the ADSS cables, which is reduced by $27 \%$, when cables get tired by the heat effect. The actual behaviour of ADSS cables under different heat conditions is modelled mathematically. Because all experiments were done under isolated conditions in the laboratory, results could be interpreted on account of corresponding real environmental conditions. Modeling consisted of descriptive analysis of variables, variance analysis and regression analysis. Logistic model is significant and suitable. In a nonlinear regression model, the magnitudes of coefficients are $a=0.50$ and $b=0.983$. Estimation of parameters and models for the nonlinear regression model is described.

\section{Acknowledgments}

This study was supported by Kirklareli University (KUBAP 009) and Uludag University (UAP(F)2010/18).

\section{References}

[1] R.H. Myers, D.C. Montgomery, C.M.A. Cook, Response Surface Methodolgy, Wiley, London 2009.

[2] R. Tsay, Analysis of Financial Time Series, Wiley Series in Probability and Statistics, Wiley, New York 2002.

[3] B. Shi, G.G. Karady, Q. Huang, M.W. Tuominen, IEEE Trans. Power Delivery 19, 1936 (2004).

[4] G.G. Karady, C.V. Nunez, R. Raghavan, IEEE Trans. Power Delivery 13, 647 (1998).

[5] E. Eroglu, I. Guney, I. Gunes, Acta Phys. Pol. A 121, 36 (2012).

[6] G. Karady, M. Tuominen, B. Han, in Proc. Power Engineering Society Summer Meeting, IEEE, 1999, p. 890.

[7] C.N. Carter, M.A. Waldron, IEE Proc. C, 139, 185 (1992).

[8] K.S. Edwards, P.D. Pedrow, R.G. Olsen, Conf. Electrical Insulation and Dielectric Phenomena, Annual Report, IEEE, 1999, p. 158.

[9] S. Rowland, N.R. Haigh, S.M. Rowland, A.J. Taha, C.N. Carter, 45th Proc. International Wire and $\mathrm{Ca}$ ble Symposium, 1996, p. 60.

[10] G. Carlton, C.N. Carter, A.J. Peacock, 12th Int. Conf. on Electricity Distribution (CIRED), 1993, p. 3.16 .

[11] G. Carlton, A. Bartlett, C. Carter, T. Parkin, Power Eng. J. 9, 7 (1995).

[12] G. Karady, S. Devarajan, IEEE Trans. Power Del., 16, 286 (2001).

[13] G.G. Karady, Q. Huang, M.N. Hernadez, M. Tuominen, Proc. IEEE Power Eng. Soc. Winter Meet., IEEE, 2001, p. 1.

[14] Q. Huang, G.G. Karady, B. Shi, M. Tuominen, Proc. IEEE Conf. Elect. Insul. Dielectric Phenomena, Annu. Rep., IEEE, 2003, p. 379.

[15] C.N. Carter, M.A. Waldron, Proc. Inst. Elect. Eng. C 139, 185 (1992).

[16] G. Karady, M. Tuominen, B. Han, Proc. Power Eng. Soc. Summer Meet., IEEE, 1999, p. 890. 